\title{
Age-hardening characteristics of a dental low-carat gold alloy with dual hardener system of In and $\mathrm{Cu}$
}

\author{
Hyo-Joung Seol • Seong-Woo Kweon • Su-Yeon Cho • \\ Gwang-Young Lee $\cdot$ Yong Hoon Kwon • Hyung-Il Kim
}

Published online: 29 October 2011

(C) The Author(s) 2011. This article is published with open access at Springerlink.com

\begin{abstract}
The age-hardening characteristics of a dental low carat gold alloy with a dual hardener system of indium (In) and $\mathrm{Cu}(33.9 \mathrm{Au}-26.2 \mathrm{Ag}-20.28 \mathrm{Cu}-9.8 \mathrm{Pd}-7.8 \mathrm{In}-2 \mathrm{Zn}$ (at $\%)$ ) were examined by observing the age hardenability and related phase transformation, microstructural changes and elemental distribution during the aging process at $400^{\circ} \mathrm{C}$. The dual hardener system by the use of both In and $\mathrm{Cu}$ provided more powerful hardening effect compared to a single-hardener system of In or $\mathrm{Cu}$, without the formation of a $\mathrm{AuCu}$ type ordered phase. The alloy showed apparent initial hardening, which was attributed to the pre-precipitation or zone formation by the help of quenched in excess vacancies. During the constant increase in hardness, the single parent phase separated into three phases, $\mathrm{Au}-\mathrm{Ag}$-based phase, $\mathrm{Au}-$ Cu-based phase containing Pd and In, and InPd-based phase, through a metastable state. Indium which was added as one of the hardeners induced initial grain boundary precipitation, followed by an expansion of the lamellar structure, which was responsible for softening. The alternative lamellar structure was composed of a $\mathrm{Cu}$-rich layer $(\mathrm{Au}-\mathrm{Cu}$-based phase containing $\mathrm{Pd}$ and In) and an Ag-rich layer (Au-Ag-based phase) replaced partly by the InPd-based phase. Separation of the Agrich layer from the $\mathrm{Cu}$-rich layer is based on the miscibility limit of $\mathrm{Ag}$ and $\mathrm{Cu}$ due to their eutectic property.
\end{abstract}

H.-J. Seol • S.-W. Kweon · S.-Y. Cho · G.-Y. Lee • Y. H. Kwon •

H.-I. Kim $(\bowtie)$

Dept. of Dental Materials,

School of Dentistry and Medical Research Institute,

Pusan National University,

Beomeo-Ri, Mulgeum-Eup,

Yangsan-Si, Gyeongsangnam-Do 626-814, South Korea

e-mail: seol222@pusan.ac.kr
Keywords Dual hardener system · Age-hardening characteristics Phase transformation $\cdot \mathrm{Au}-\mathrm{Ag}-\mathrm{Cu}-\mathrm{Pd}-\mathrm{In}$. Alternative lamellar structure

\section{Introduction}

The recent increase in gold price has increased the demand for alternative dental alloys with lower Au contents. Dental low-carat gold alloys are alternative dental alloys with a higher $\mathrm{Ag}$ and Pd content compared to the high-carat gold alloy. The alloy composed of only $\mathrm{Au}, \mathrm{Ag}$, and Pd do not exhibit age hardenability, which is essential for dental crowns and bridges to withstand the occlusial force [1]. Accordingly, the well-known hardener, $\mathrm{Cu}$, is added to dental low-carat gold alloys to achieve the age hardenability by forming a $\mathrm{AuCu}$ type ordered phase or by precipitating a $\mathrm{Cu}$-based phase [2-6]. In such cases, if there is insufficient $\mathrm{Au}$ content for the formation of the $\mathrm{AuCu}$ phase or if $\mathrm{Cu}$ preferentially forms a stable phase with other elements in the as-cast state, the hardening effect of $\mathrm{Cu}$ will be unsatisfactory. Therefore, the extra $\mathrm{Cu}$ content, which could not act as a hardener, will exhibit preferential corrosion of the less noble phase. To avoid this, an element that exhibits a hardening effect together with sufficient tarnish and corrosion resistance was requested. Recently, indium (In) has been replacing $\mathrm{Cu}$ in an alternative $\mathrm{Ag}-\mathrm{Pd}$ alloy because it exhibits age hardenability by the precipitation of an In-based phase from the Ag-rich matrix with sufficient tarnish and corrosion resistance [7,8]. On the other hand, for dental low-carat gold alloys, the use of relatively large amounts of In as a hardener is unfamiliar because In is a minor ingredient that has been added only to improve the castability by decreasing the melting temperature. In recent studies on the age hardenability of dental 
alloys, it was reported that the In-added $\mathrm{Cu}$-free $\mathrm{Ag}-\mathrm{Pd}-\mathrm{Au}$ alloy (41.7 Ag-23 Pd-11.8 Au-16.7 In-6.8 Zn (at\%)) aged at $350-450^{\circ} \mathrm{C}$ and the In-added $\mathrm{Cu}$-free $\mathrm{Au}-\mathrm{Ag}-\mathrm{Pd}$ alloy (41.3 Au-39.8 Ag-13.7 Pd-5.2 In (at\%)) aged at $450-550^{\circ} \mathrm{C}$ showed much lower age hardenability than the In-free $\mathrm{Ag}-\mathrm{Pd}-\mathrm{Cu}-\mathrm{Au}$ alloy $(53.9 \mathrm{Ag}-20.8 \mathrm{Pd}-14.1 \mathrm{Cu}-6.7$ $\mathrm{Au}-4 \mathrm{Zn}(\mathrm{at} \%))$ aged at $350-450^{\circ} \mathrm{C}[6,9,10]$. By considering their results, which shows that In provides a weaker hardening effect than $\mathrm{Cu}$, it was hypothesized that the adoption of a dual hardener system by $\mathrm{In}$ and $\mathrm{Cu}$ would have a more powerful hardening effect.

In the present study, a dental low carat $\mathrm{Au}-\mathrm{Ag}-\mathrm{Cu}-\mathrm{Pd}$ alloy with a relatively high In content was studied. The hardening effects of the alloy were expected to be improved using a dual hardener system through the addition of $\mathrm{In}$ and $\mathrm{Cu}$, but multiphase formation, which can be disadvantageous in terms of tarnish and corrosion resistance, was also a concern due to the relatively large $\mathrm{In}$ and $\mathrm{Cu}$ content. In this complicated alloy system, it is difficult to predict the process of phase transformation. The aim of this study is to elucidate the agehardening characteristics of a dental low-carat gold alloy with a dual hardener system of $\mathrm{In}$ and $\mathrm{Cu}$ by characterizing the age hardenability and related phase transformation, microstructural changes, and elemental distribution.

\section{Materials and methods}

Specimen alloy

The alloy used in the present study was a yellow $\mathrm{Au}-$ $\mathrm{Ag}-\mathrm{Cu}-\mathrm{Pd}-\mathrm{In}$ alloy used in crowns and bridge fabrications (Aurium52HN, Aurium research, USA), which belongs to type 3 alloy by the ISO classification (ISO 22674:2006(E)). Table 1 lists the chemical composition of the alloy. The initial shape of the specimen was plate-like with dimensions of $12 \times 8 \times 1 \mathrm{~mm}$ and was procured in a rolled and annealed state.

\section{Hardness test}

Before hardness testing, the specimens were solutiontreated at $750^{\circ} \mathrm{C}$ for 15 min under an argon atmosphere and then rapidly quenched into ice brine to preclude thermal changes on cooling. They were subsequently aged at $400^{\circ} \mathrm{C}$, as recommended by the manufacturer. All aging

Table 1 Chemical composition of the alloy

\begin{tabular}{llllllll}
\hline Composition & $\mathrm{Au}$ & $\mathrm{Ag}$ & $\mathrm{Cu}$ & $\mathrm{Pd}$ & $\mathrm{In}$ & $\mathrm{Zn}$ & $\mathrm{Ir}$ \\
\hline wt.\% & 51.9 & 22 & 10 & 8.07 & 7 & 1 & 0.03 \\
at\% & 33.9 & 26.2 & 20.28 & 9.8 & 7.8 & 2 & 0.02 \\
\hline
\end{tabular}

was done in a molten salt bath $\left(25 \% \mathrm{KNO}_{3}+30 \% \mathrm{KNO}_{2}+\right.$ $25 \% \mathrm{NaNO}_{3}+20 \% \mathrm{NaNO}_{2}$ ), followed by quenching into ice brine. Hardness measurements were made using a Vickers microhardness tester (MVK-H1, Akashi Co., Japan) with a load of $300 \mathrm{~g}-\mathrm{f}$ and a dwell time of $10 \mathrm{~s}$. Vickers hardness results were recorded as the average values of five measurements.

\section{X-ray diffraction study}

For the X-ray diffraction (XRD) study, powder specimens which passed through a 300-mesh screen were obtained by filing the plate-like samples. After being vacuum sealed in a silica tube and solution-treated at $750^{\circ} \mathrm{C}$ for $15 \mathrm{~min}$, they were isothermally aged at $400^{\circ} \mathrm{C}$ for various periods of time in a molten salt bath, and then quenched into ice brine. The $\mathrm{X}$-ray diffraction profiles were recorded by an X-ray diffractometer (XPERT-PRO, Philips, Netherlands). The X-ray diffractometer was operated at $30 \mathrm{kV}$ and $40 \mathrm{~mA}$, using nickel-filtered $\mathrm{Cu} \mathrm{K} \alpha$ radiation. The scanning rate of a goniometer was $2^{\circ}(2 \theta / \mathrm{min})$.

Field emission scanning electron microscopic observations

For the field emission scanning electron microscopic observations (FE-SEM), the plate-like samples were subjected to the required heat treatment and then prepared by utilizing standard metallographic techniques. A freshly prepared aqueous solution of $10 \%$ potassium cyanide and $10 \%$ ammonium persulfate $\left(\left(\mathrm{NH}_{4}\right)_{2} \mathrm{~S}_{2} \mathrm{O}_{8}\right)$ was used for the final etching of the samples. The specimens were examined at $15 \mathrm{kV}$ using a field emission scanning electron microscope (JSM-6700 F, JEOL, Japan).

\section{Energy dispersive spectrometer analysis}

Energy dispersive spectrometer (EDS) analysis was done to observe the distributional changes of each element in the alloy during the aging process. The specimens were prepared in the same manner as was used for the scanning electron microscopic observations. Energy dispersive spectrometer analysis was performed using a field emission scanning electron microscope (JSM-6700 F, JEOL, Japan) equipped with an energy dispersive X-ray spectrometer (INCA x-sight, Oxford Instruments Ltd., UK).

\section{Results and discussion}

Age-hardening behavior

Figure 1 shows the isothermal age hardening curve of the alloy solution-treated at $750^{\circ} \mathrm{C}$ for $15 \mathrm{~min}$ and aged at 


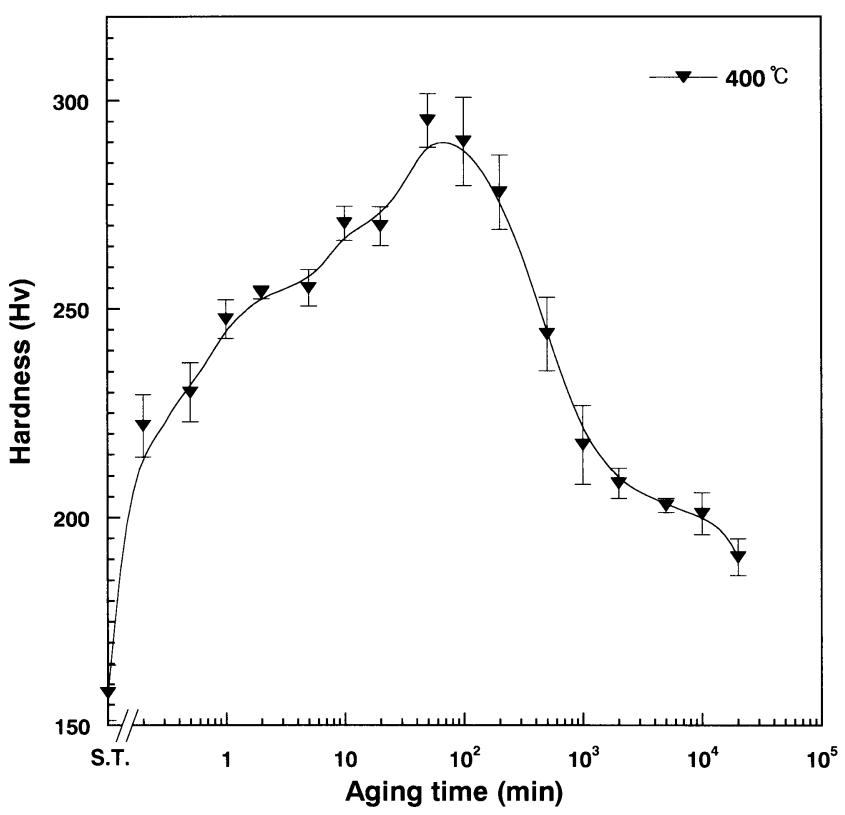

Fig. 1 Isothermal age hardening curve of the alloy aged at $400^{\circ} \mathrm{C}$

$400^{\circ} \mathrm{C}$ for various times. The hardness increased apparently from 158 to $222 \mathrm{Hv}$ after $12 \mathrm{~s}$ aging. Therefore, it was supposed that the quenched in excess vacancies attributed to atomic diffusion, resulting in an instant increase in hardness.

It was reported that the addition of In to $\mathrm{AuCu}$ alloy reduced the age hardenability at low temperatures, which is controlled by the number of free vacancies and diffusion [11]. Although In has a low melting temperature, which is advantageous for vacancy diffusion, its large binding energy with vacancies decreases the number of effective free vacancies for diffusion, which retards the age hardenability at low temperatures [11-13]. On the other hand, in the present study, even with a relatively large In content, the alloy showed apparent initial hardening, which was attributed to quenched in excess vacancies. This might be attributed to the Pd content, which tends to form a stable phase preferentially with In, as will be discussed in the XRD studies [1].

After $12 \mathrm{~s}$, the hardness increased constantly, and the maximum hardness, $295 \mathrm{Hv}$, was obtained at an aging time of $50 \mathrm{~min}$. The hardness began to decrease considerably until an aging time of $2,000 \mathrm{~min}$. Subsequently, the decreasing rate of hardness was retarded until an aging time of 20,000 min. The maximum hardness, $295 \mathrm{Hv}$, obtained in the present study was slightly higher than the value obtained in the In-free $\mathrm{Ag}-\mathrm{Pd}-\mathrm{Cu}-\mathrm{Au}$ alloy aged at $350-450^{\circ} \mathrm{C}(280 \mathrm{Hv})$ and much higher than the value, $220 \mathrm{Hv}$, obtained in the $\mathrm{Cu}$-free $\mathrm{Ag}-\mathrm{Pd}-\mathrm{Au}-\mathrm{In}$ alloy aged at $350-450^{\circ} \mathrm{C}$ and the $\mathrm{Cu}-$ free $\mathrm{Au}-\mathrm{Ag}-\mathrm{Pd}-\mathrm{In}$ alloy aged at $450-550^{\circ} \mathrm{C}[6,9,10]$. Hence, the dual hardener system by the use of both $\mathrm{In}$ and $\mathrm{Cu}$ was believed to have provided more powerful hardening effect compared to a single-hardener system of In or $\mathrm{Cu}$.

Phase transformation

To understand the mechanism of age hardening, the phase transformation with aging was observed by XRD. Figure 2 shows the variations of the XRD pattern during $400^{\circ} \mathrm{C}$ isothermal aging. In the solution-treated specimen, a facecentered cubic ( $\mathrm{fcc}$ ) single phase was obtained. The fcc phase $(\alpha)$ had a lattice parameter of $a_{200}=0.40 \mathrm{~nm}$. By aging the solution-treated specimen for $20,000 \mathrm{~min}$, the parent fcc $\alpha$ phase was transformed to an fcc $\alpha_{1}$ phase with slight increase in the lattice parameter, $a_{200}=0.406 \mathrm{~nm}$ by precipitating the CsCl-type body-centered cubic (bcc) $\beta$ phase with a lattice parameter of $a_{211}=0.321 \mathrm{~nm}$, and the fcc $\alpha_{2}$ phase with $a_{200}=0.387 \mathrm{~nm}$. The InPd phase was reported to be a $\mathrm{CsCl}$ type bcc structure with a lattice parameter of $a=0.325 \mathrm{~nm}$ [14]. From the alloy composition and lattice parameter of each phase, the $\beta$ and $\alpha_{2}$ phase was to be respectively, the InPd-based phase and $\mathrm{Au}-\mathrm{Cu}$-based phase containing Pd and In. The $\alpha_{2}$ phase had a similar lattice parameter to that of $\operatorname{Pd}(a=0.38908 \mathrm{~nm})$ even with a relatively high $\mathrm{Cu}$ with small atomic size [15]. This was attributed to the In content with a relatively large atomic

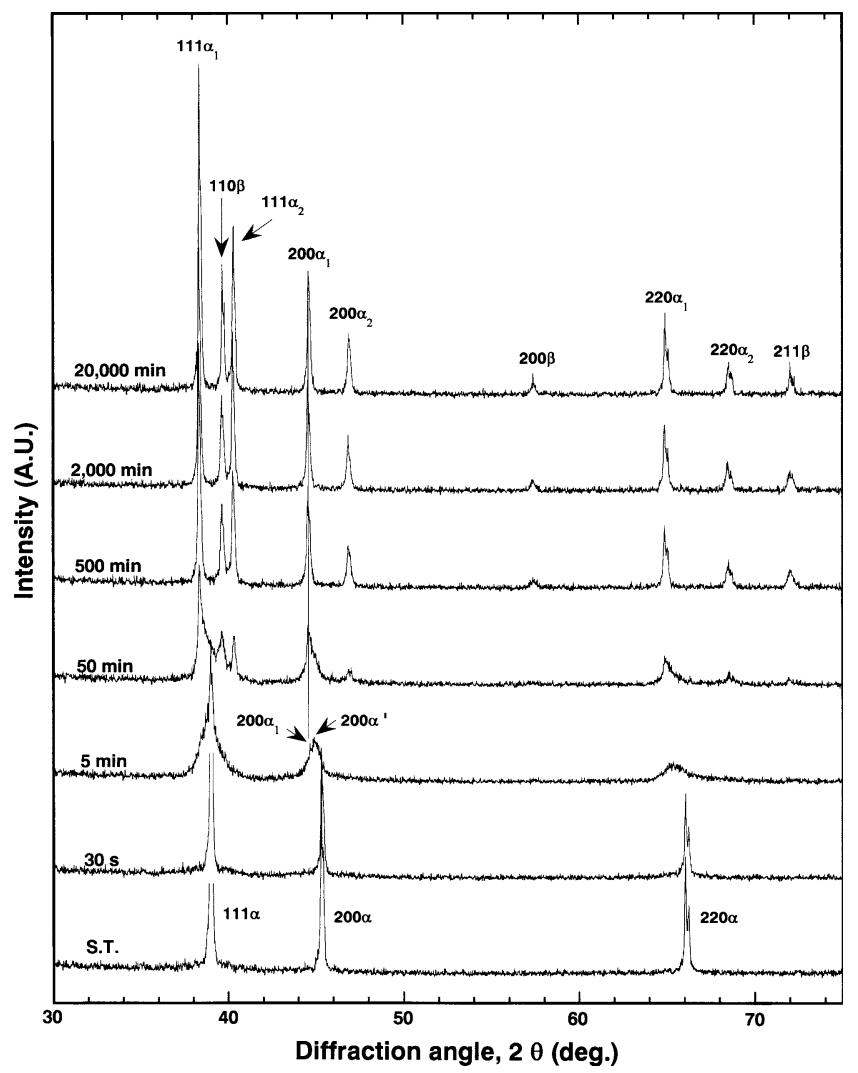

Fig. 2 Variations of the XRD patterns as a function of isothermal aging time at $400^{\circ} \mathrm{C}$ 
size in the $\alpha_{2}$ phase [15] as shown in the EDS results. From the above, the age hardenability of the alloy was related to phase separation into three phases of the $\mathrm{Au}-\mathrm{Ag}$-based phase, $\mathrm{Au}-\mathrm{Cu}$-based phase containing Pd and In, and InPdbased phase. In a study on the age-hardening mechanism of the 41.7 Ag-30.15 Au-20.9 Cu-4.7 Pd-1.1 In (at\%) alloy aged at $400^{\circ} \mathrm{C}$, the $\mathrm{AuCu}$-type ordered-phase attributed to an increase in hardness [16]. In the present study, although the $\mathrm{Au}$ and $\mathrm{Cu}$ content was similar to the above alloy, the formation of the AuCu-type ordered-phase was not observed.

The changes in the XRD patterns during isothermal aging at $400^{\circ} \mathrm{C}$ were examined with respect to the isothermal age hardening curve at $400^{\circ} \mathrm{C}$ (Fig. 1). The hardness increased apparently from 158 to $222 \mathrm{Hv}$ after 12$\mathrm{s}$ aging. On the other hand, there were no apparent changes in the XRD pattern until 30-s aging. It is known that preprecipitation or zone formation does not result in a shift in the fundamental diffraction peaks $[17,18]$. Therefore, the quenched in excess vacancies assisted the diffusion of the solute, resulting in pre-precipitation or zone formation. At an aging time of $5 \mathrm{~min}$, the hardness increased to $255 \mathrm{Hv}$. In the corresponding XRD pattern, the diffraction peaks of the $\alpha$ phase became broader with a concomitant decrease in peak intensity. The (200) $\alpha$ peak shifted toward a lower diffraction angle side and was divided into two, indicating the coexistence of a metastable phase $\left(\alpha^{\prime}\right)$ with the final stable phase $\left(\alpha_{1}\right)$. Therefore, the final $\alpha_{1}$ phase formed through a metastable state by the precipitation of $\alpha_{2}$ and $\beta$. The metastable phase has a lattice parameter between the parent phase and final stable phase. Therefore, the formation of a metastable phase must have minimized the accumulation of the lattice strain in the matrix by reducing the gap in the lattice parameters among the parent and product phases.

At an aging time of $50 \mathrm{~min}$, when the maximum hardness value, $295 \mathrm{Hv}$, was obtained, the $110 \beta$ and 111 $\alpha_{2}$ peaks became strong and the parent $\alpha$ phase was in the process of transforming into the stable $\alpha_{1}$ phase. The asymmetrically broad (200) $\alpha_{1}$ peak indicated that the metastable $\alpha$ phase still remained. This suggests that both the formation of the metastable $\alpha^{\prime}$ phase and its subsequent transformation into the stable $\alpha_{1}$ phase attributed to an increase in hardness. On the other hand, from the fact that a further increase in hardness stopped at $50 \mathrm{~min}$ when the phase transformation was still in progress, it was supposed that some microstructural changes, which are related to softening were already initiated, as will be shown in the FE-SEM observations.

By further aging until $500 \mathrm{~min}$ when the peak hardness decreased to $244 \mathrm{Hv}$, the parent $111 \propto$ peak disappeared and the phase transformation was almost complete. Until an aging time of $20,000 \mathrm{~min}$ when a drastic decrease in hardness to $190 \mathrm{Hv}$ had occurred, the broad diffraction peaks became sharp. From the above, during the period of the hardness decrease, there was no apparent change in the XRD patterns except for peak sharpening. This peak broadening and then sharpening implies the introduction and then release of lattice strain in the matrix, resulting in softening [19-22]. Therefore, the microstructural changes related to the release of lattice strain were supposed in the later stage of the aging process.

\section{Microstructural changes}

FE-SEM observations were performed to clarify the microstructural changes occurring during the hardness changes. Figure 3 shows FE-SEM micrographs of $\times 1,000$ and $\times 40,000$ for the specimen solution treated at $750^{\circ} \mathrm{C}$ for $10 \mathrm{~min}$ (a) and aged at $400^{\circ} \mathrm{C}$ for the following time periods: $50,500,2,000$, and $20,000 \mathrm{~min}$. In the solutiontreated specimen (Fig. 3a), a single phase was obtained, as indicated in the XRD pattern. In dental alternative alloys containing high Pd levels, it is difficult to obtain a singlephase solid solution because Pd preferentially forms an additional stable phase with $\mathrm{In}$ or $\mathrm{Cu}$ in the form of a particle-like structure $[6,9,10]$. In such a case, the age hardenability is obtained only by the remaining In or $\mathrm{Cu}$ which did not constitute the particle-like structure $[6,9$, 10]. In the present alloy with a dual hardener system of In and $\mathrm{Cu}$, however, the particle-like structure was not formed in the solution-treated state. Hence, the total amounts of $\mathrm{In}$ and $\mathrm{Cu}$ might have participated in the phase transformation process. This also imparted powerful age hardenability to the present alloy system compared to that with a single-hardener system of $\mathrm{In}$ or $\mathrm{Cu}$, as mentioned above $[6,9,10]$.

In the specimen aged for $50 \mathrm{~min}(\mathrm{~B})$ when the maximum hardness value was obtained, no change in the grain interior was observed, and the limited area of the grain boundaries was replaced by the lamellar structure. In the corresponding XRD pattern, the parent phase was in the process of transforming into the stable phases through the metastable state, resulting in a multiphased matrix. Considering the gap in the lattice parameters among the existing phases, the grain interior was thought to have apparent internal strain. Therefore, to release the internal lattice strain, the lamellarforming grain boundary reaction, which is a well-known softening mechanism, was initiated, as will be further mentioned [3, 23, 24].

By further aging until 500 min (C), besides expansion of the grain boundary lamellar structure, the grain interior structure changed into a complex structure with a finer nature than the grain boundary structures, as shown in (C-2). By further aging for 2,000 $\mathrm{min}$ (D), the grain boundary lamellar structure covered almost the entire matrix, and the complex grain interior 
Fig. 3 FE-SEM micrographs of specimens a solution-treated at $700^{\circ} \mathrm{C}$ for $10 \mathrm{~min}$ and aged at $400^{\circ} \mathrm{C}$ for b $50 \mathrm{~min}$, c $500 \mathrm{~min}$ d 2,000 $\mathrm{min}$, and e $20,000 \mathrm{~min}$ (1) $\times 1,000,(2) \times 40,000$
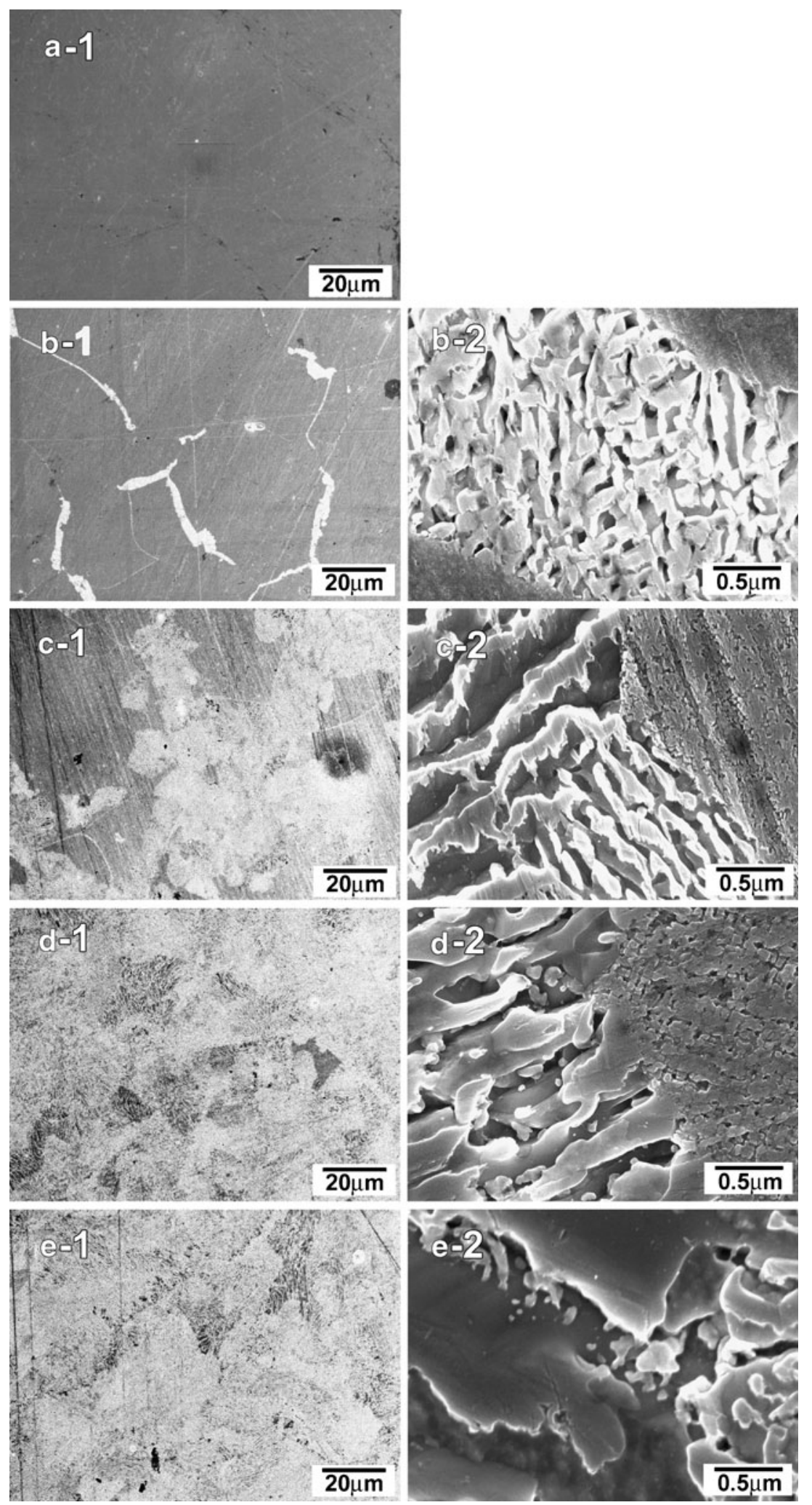

structure was further coarsened. At an aging time of $20,000 \mathrm{~min}$, the inter-lamellar spacing was further coarsened (E-2), which corresponded to a further decrease in hardness.
From the above, during the hardness decrease, there were apparent microstructural changes. The expansion of the lamellar structure and further coarsening reduces the interphase boundaries containing lattice strain, which 
Fig. 4 FE-SEM micrographs of specimen aged at $400^{\circ} \mathrm{C}$ for a $50 \mathrm{~min}$, b $500 \mathrm{~min}$, and $\mathbf{c}$ 20,000 min: features arrowed $M, G b$, and $L$ are discussed in text
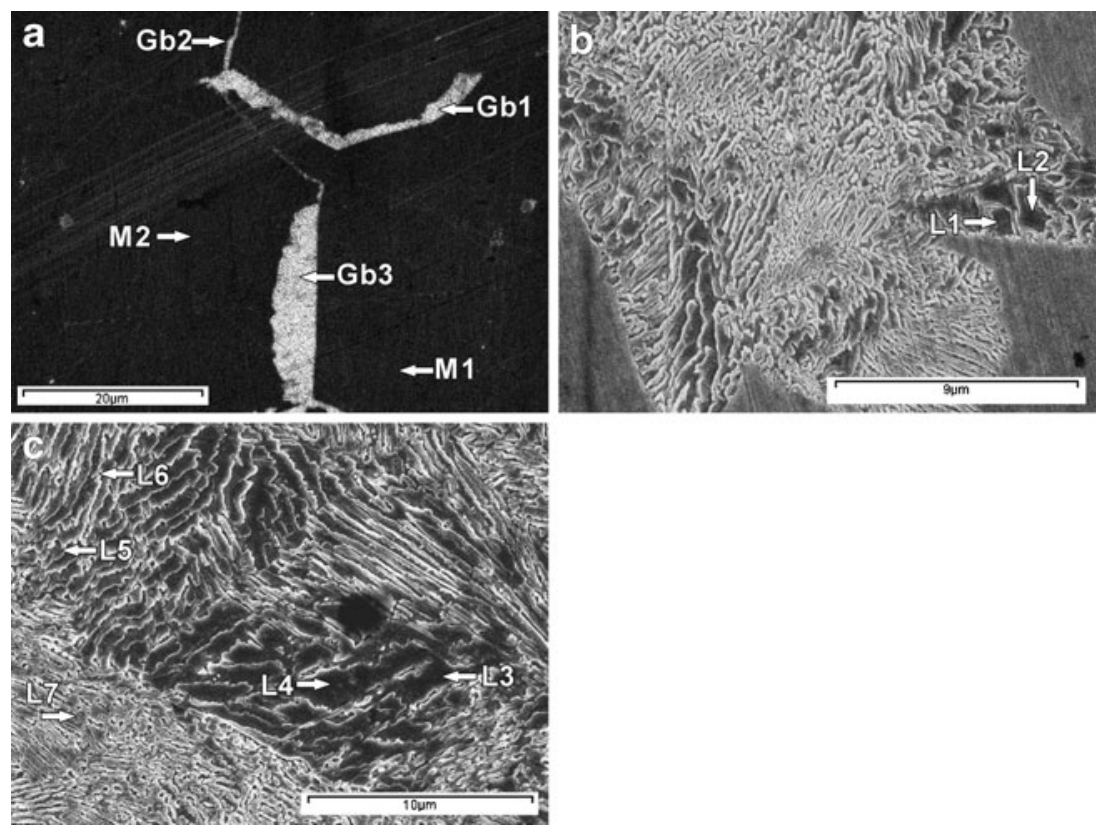

results in softening $[3,23,24]$. The decreasing rate in hardness was proportional to the replacing ratio of the matrix by the lamellar structure considering the FE-SEM results and the hardness changed from $50 \mathrm{~min}$ until 2,000 $\mathrm{min}$. On the other hand, further coarsening of the interlamellar spacing after the entire replacement of the lamellar structure did not result in severe softening as much as expansion of the lamellar structure.

\section{Changes in the elemental distribution}

The changes in elemental distribution with aging time were examined by EDS. Figure 4 shows FE-SEM micrographs of the specimen aged at $400^{\circ} \mathrm{C}$ for $50 \mathrm{~min}$ (a) when the maximum hardness, $295 \mathrm{Hv}$, was obtained, $500 \mathrm{~min}$; (b) when the hardness decreased to $244 \mathrm{Hv}$, and $20,000 \mathrm{~min}$; (c) when drastic softening down to $190 \mathrm{Hv}$ was observed. The regions analyzed, as marked by the arrow, were the matrix $(\mathrm{M})$, grain boundary precipitates $(\mathrm{Gb})$, and each layer of the lamellar structures (L). The results are shown in Table $2 \mathrm{~A}-\mathrm{C}$ regions. In the specimen aged for 50 min (A), the grain boundary lamellar precipitates $(\mathrm{Gb})$ showed apparently less $\mathrm{Cu}$ with slightly more $\mathrm{Pd}$ and $\mathrm{In}$ with or without an increase in Ag compared to the alloy composition listed in Table 1. The Au content did not show apparent changes, and the $\mathrm{Zn}$ content did not show consistency. The corresponding XRD results showed that the single parent phase was in the process of separating into three phases; $\mathrm{Au}-\mathrm{Ag}$-based phase, $\mathrm{Au}-\mathrm{Cu}$-based phase containing Pd and In, and InPd-based phase. By considering the XRD results together with the EDS results, such a change at $\mathrm{Gb}$ was obtained from both the Au-Ag-based phase and InPd-based phase, as will be further discussed.
Considering the large sampling spot size and that $\mathrm{Ag}$ is one of the major components, the grain boundary precipitates are thought to be composed mainly of In and Pd. These results suggest that In, which was added as a hardener, induced the initial grain boundary precipitation which is responsible for softening. Several studies have reported that the initial grain boundary precipitation occurred mainly by In and Pd in dental gold alloys which were hardened by formation of the $\mathrm{AuCu}$ I phase $[16,25]$. The multiphased matrix (M) showed the same composition as that of the alloy of the solution-treated state due to the large sampling spot size, which covers all the submicroscopic precipitates in the matrix.

Table 2 EDS analysis at the regions marked in Fig. $4 a-c$

\begin{tabular}{lccllll}
\hline & $\mathrm{Au}$ & $\mathrm{Ag}$ & $\mathrm{Cu}$ & $\mathrm{Pd}$ & $\mathrm{In}$ & $\mathrm{Zn}$ \\
\hline \multicolumn{2}{l}{$\begin{array}{l}\text { A region (at \%) } \\
\text { Gb1 }\end{array}$} & & & & & \\
Gb2 & 32.6 & 31.1 & 14 & 11.6 & 9.3 & 1.4 \\
Gb3 & 33.5 & 25.7 & 14.4 & 12.2 & 9.9 & 4.5 \\
M1 & 33.3 & 24.3 & 20.2 & 9.3 & 8 & 4.9 \\
M2 & 36.2 & 24.7 & 20.8 & 8.0 & 7.5 & 2.8 \\
B region (at \%) & & & & & \\
L1 & 31.6 & 16.1 & 26.3 & 12.8 & 10.4 & 2.8 \\
L2 & 34.6 & 30.4 & 12.2 & 11.2 & 10 & 1.6 \\
C region (at \%) & & & & & \\
L3 & 30.5 & 14 & 27.8 & 15.8 & 8.5 & 3.4 \\
L4 & 29.1 & 31.6 & 9.9 & 13.5 & 12.6 & 3.3 \\
L5 & 31 & 10.4 & 26.6 & 17 & 10 & 5 \\
L6 & 27.7 & 21.3 & 13.1 & 19.3 & 11.6 & 7 \\
L7 & 34.7 & 36.2 & 9.8 & 8.9 & 7.7 & 2.7 \\
\hline
\end{tabular}


In the specimen aged for $500 \mathrm{~min}$ (B), the (L1) layer of the coarse lamellar structure had a lower Ag content and higher $\mathrm{Cu}$ content, and the neighboring (L2) layer had a higher $\mathrm{Ag}$ content and lower $\mathrm{Cu}$ content compared to the alloy composition listed in Table 1 . In and Pd increased slightly in both layers. Such a tendency was also observed in the specimen aged for 20,000 $\mathrm{min}(\mathrm{C})$. The coarse two neighboring layers $(\mathrm{L} 3,4)$ had a slightly higher In and Pd content, and were distinguished by the contradictory content of $\mathrm{Ag}$ and $\mathrm{Cu}$. Considering the XRD results together, the (L3) layer of the coarse lamellar was composed of the $\mathrm{Au}-\mathrm{Cu}$-based phase containing $\mathrm{Pd}$ and In, and the (L4) layer was composed of both the $\mathrm{Au}-\mathrm{Ag}$ based phase and the InPd-based phase. The finer layer (L5) and neighboring layer (L6) also showed a similar result to that of the (L3) and (L4) layers.

Besides the Ag-rich region with slightly increased In and Pd content, there was also the Ag-rich region (L7) with slightly less Pd and In. From such a discrepancy of the In and Pd content in the Ag-rich regions, it was suggested that the Ag-rich layer, which was composed of the $\mathrm{Au}-\mathrm{Ag}$ based phase, was replaced partly by the InPd-based phase, and was separated from the $\mathrm{Cu}$-rich layer composed of the $\mathrm{Au}-\mathrm{Cu}$-based phase containing $\mathrm{Pd}$ and $\mathrm{In}$. The separation of the Ag-rich layer from the $\mathrm{Cu}$-rich layer is based on the miscibility limit of $\mathrm{Ag}$ and $\mathrm{Cu}$ due to their eutectic property according to the binary phase diagram of $\mathrm{Ag}$ and $\mathrm{Cu}$ [1]. On the other hand, Au has complete solubility with both $\mathrm{Ag}$ and $\mathrm{Cu}$ at all atomic ratios, which corresponds to a relatively constant $\mathrm{Au}$ content in both the Ag-rich and $\mathrm{Cu}$-rich layers [1].

\section{Summary}

The age hardening characteristics of a dental low carat gold alloy with a dual hardener system of $\mathrm{In}$ and $\mathrm{Cu}$ (33.9 Au-26.2 Ag-20.28 Cu-9.8 Pd-7.8 In-2 Zn (at\%)) was examined by observing the age hardenability and related phase transformations, microstructural changes and elemental distribution during aging at $400^{\circ} \mathrm{C}$. The results are as follows.

1. The dual hardener system of $\mathrm{In}$ and $\mathrm{Cu}$ provided a powerful hardening effect without the formation of the $\mathrm{AuCu}$-type ordered phase in the $\mathrm{Au}-\mathrm{Ag}-\mathrm{Cu}-\mathrm{Pd}$ alloy with a relatively high In content.

2. The alloy showed apparent initial hardening that was attributed to pre-precipitation or zone formation by the aid of quenched in excess vacancies.

3. During the constant increase in hardness, the single parent phase separated into three phases, $\mathrm{Au}-\mathrm{Ag}$-based phase, $\mathrm{Au}-\mathrm{Cu}$-based phase containing $\mathrm{Pd}$ and In, and InPd-based phase, through a metastable state.
4. Indium added as a hardener induced initial grain boundary precipitation, followed by an expansion of the lamellar structure, which is responsible for softening.

5. The miscibility limit of $\mathrm{Ag}$ and $\mathrm{Cu}$ resulted in the formation of alternative lamellar structure which was composed of the $\mathrm{Cu}$-rich layer $(\mathrm{Au}-\mathrm{Cu}$-based phase containing $\mathrm{Pd}$ and $\mathrm{In}$ ) and the Ag-rich layer ( $\mathrm{Au}-\mathrm{Ag}$ based phase) replaced partly by the InPd-based phase.

Open Access This article is distributed under the terms of the Creative Commons Attribution License which permits any use, distribution and reproduction in any medium, provided the original author(s) and source are credited.

\section{References}

1. Massalski TB (1990) Binary alloy phase diagrams, 2nd edn. ASM International, Materials Park, pp 12-13 (Ag-Au), 28-29 (Ag-Cu), 72-74 (Ag-Pd), 358-362 (Au-Cu), 409-410 (Au-Pd), 2271-2273 (In-Pd)

2. Yasuda K, Ohta M (1982) Difference in age-hardening mechanism in dental gold alloys. J Dent Res 61:473-479

3. Yasuda K (1987) Age-hardening and related phase transformations in dental gold alloys. Gold bull 20:90-103

4. Yasuda K, Hisatsune K (1993) Microstructure and phase transformations in dental gold alloys. Gold bull 26:50-66

5. Hisatsune K, Shiraishi T, Takuma Y, Tanaka Y, Luciano RH (2007) Two different types of age-hardening behaviors in commercial dental gold alloys. J Mater Sci Mater Med 18:577-581

6. Seol HJ, Kim GC, Son KH, Kwon YH, Kim HI (2005) Hardening mechanism of an Ag-Cu-Pd-Au dental casting alloy. J Alloys Compd 387:139-146

7. Hattori M, Tokizaki T, Matsumoto M, Oda Y (2010) Corrosion properties of $\mathrm{Ag}-\mathrm{Au}-\mathrm{Cu}-\mathrm{Pd}$ system alloys containing indium. Bull tokyo dental coll 51:7-13

8. Cho SY, Lee GY, Kwon YH, Kim HI, Seol HJ (2011) Agehardening characteristic of a $\mathrm{Cu}$-free Ag-Pd alloy containing high In. J Korean Res Soc Dent Mater 38:91-100

9. Seol HJ, Son KH, Yu CH, Kwon YH, Kim HI (2005) Precipitation hardening of a Cu-free Au-Ag-Pd-In dental alloy. J Alloys Compd 402:130-135

10. Lee HK, Moon HM, Seol HJ, Lee JE, Kim HI (2004) Age hardening by dendrite growth in a low-gold dental casting alloy. Biomaterials 25:3869-3875

11. Ohta M, Shiraishi T, Nakagawa M, Matsuya S (1994) Dental gold alloys with age-hardenability at intraoral temperature. J Mater Sci 29:2083-2086

12. Ouchida R, Shiraishi T, Nakagawa M, Ohta M (1995) Effects of $\mathrm{Au} / \mathrm{Cu}$ ratio and gallium content on the low-temperature agehardening in Au-Cu-Ga alloys. J Mater Sci 30:3863-3866

13. Shewmon P (1989) Diffusion in solids, 2nd edn. TMS, Warrendale, $\mathrm{PA}, \mathrm{p} 147$

14. Hellner E, Laves F (1947) Kristallchemie des In und $\mathrm{Ga}$ in Legierungen mit einigen Übergangselementen $(\mathrm{Ni}, \mathrm{Pd}, \mathrm{Pt}, \mathrm{Cu}, \mathrm{Ag}$ und $\mathrm{Au}) . \mathrm{Z}$ Naturforschg 2a:177-183

15. Cullity BD (1978) Elements of X-ray diffraction, 2nd edn. Addison-Wesley, Massachusetts, pp 506-507 
16. Jeon GH, Kwon YH, Seol HJ, Kim HI (2008) Hardening and overaging mechanisms in an $\mathrm{Au}-\mathrm{Ag}-\mathrm{Cu}-\mathrm{Pd}$ alloy with In additions. Gold bull 41:302-308

17. Ohta M, Hisatsune K, Yamane M (1979) Age-hardening of AgPd-Cu dental alloy. J Less-common Metals 65:11-21

18. Shiraishi T, Ohta M (2002) Age-hardening behaviors and grain boundary discontinuous precipitation in a Pd-free gold alloy for porcelain bonding. J Mater Sci Mater Med 13:979-983

19. Tanaka Y, Udoh K, Hisatsune K, Yasuda K (1998) Early stage of ordering in stoichiometric AuCu alloy. Mater Trans JIM 39:87-94

20. Kim HI, Ahn HK, Lee HK, Hisatsune K, Seol HJ, Takuma Y (1999) Isothermal age-hardening behaviour in a multi-purpose dental casting alloy. Dent Mater J 18:314-323
21. Suryanarayana C, Norton MG (2003) X-ray diffraction: a practical approach, 1st edn. Springer, New York, pp 207-210

22. Kawashima I, Ohno H, Sarkar NK (2000) Effect of Pd or Au addition on age-hardening in AgMn-based alloys. Dent Mater 16:75-79

23. Hisatsune K, Udon K, Nakagawa M (1990) Aging behaviour in a dental low carat gold alloy and its relation to CuAuII. J Lesscommon Metals 160:247-258

24. Hisatsune K, Udon KI (1991) Age-haradening characteristics in an $\mathrm{AuCu}-14$ at.\%Ag alloy. J Alloys Compd 176:269-283

25. Seol HJ, Noh DJ, Lee SH, Kwon YH, Kim HI (2008) Agehardening by the formation of metastable phases in an In-added Au-Ag-Cu-Pd alloy. Materials Characterization 59:1190-1195 